\title{
How international are geography journals? Not international enough.
}

\section{Cite:}

Imhof, N., \& Müller, M. (2020). How international are geography journals? Not international enough. Environment and Planning A: Economy and Space.

https://doi.org/10.1177/0308518X20907608

Nadja Imhof (nadja.imhof@,unil.ch| Department of Geography and Sustainability, University of Lausanne, Switzerland | ORCID: 0000-0002-5164-141X)

Martin Müller (martin@martin-muller.net | www.-martin-muller.net | Department of Geography and Sustainability, University of Lausanne, Switzerland | ORCID: 0000-0002-07344311)

\begin{abstract}
As English is advancing to become the world's academic lingua franca, English-language journals increasingly need to reflect knowledge production on a global scale. Our graphic shows how the majority of geography journals still remain strongly anchored in Anglophone countries. A few journals, however, lead the way in the decolonial imperative to decentre knowledge production.
\end{abstract}

\section{Keywords}

Geopolitics of knowledge, knowledge production, decoloniality, Anglophone hegemony, geography

\section{Main text}

English has quickly become the world's de facto lingua franca for academic exchange. Englishlanguage journals therefore have the opportunity, and the responsibility, to shape academic discourse and knowledge production on a global scale. Many of geography's leading journals bill themselves in their mission statements as 'international journals', 'striving for international authorship and readership' (Social \& Cultural Geography: website). But how international are geography journals really? And to what extent do they reach beyond the Anglosphere?

In our 'universe of geography journals' in Figure 1, we examined 21 English-language journals in geography with regard to the participation of academics from non-Anglophone countries as authors (y-axis) and editorial board members (x-axis). While authors are the original producers of knowledge, board members, along with editors, act as crucial gatekeepers in the review and decision process. The scatter plot visualizes the position of journals in four quadrants, according to whether they are more or less Anglophone than the means for board members $(71.22 \%$ Anglophone authors; vertical line) and authors (80.43\% Anglophone editorial board members; horizontal line).

The majority of journals (12 journals) cluster in the small, top right quadrant of the AngloAmerican core, where journals are more Anglophone than the mean for both authors and board members. There are only a handful of journals that are less Anglophone than average on both dimensions, represented as 'emerging cosmopolitans' in the large bottom left quadrant. A fair international representation, which would take as its yardstick the share of the Anglophone population in the world population (ca. 7\%), would see journals cluster in the area marked as 'terra incognita'. 
Pre-Print Version 


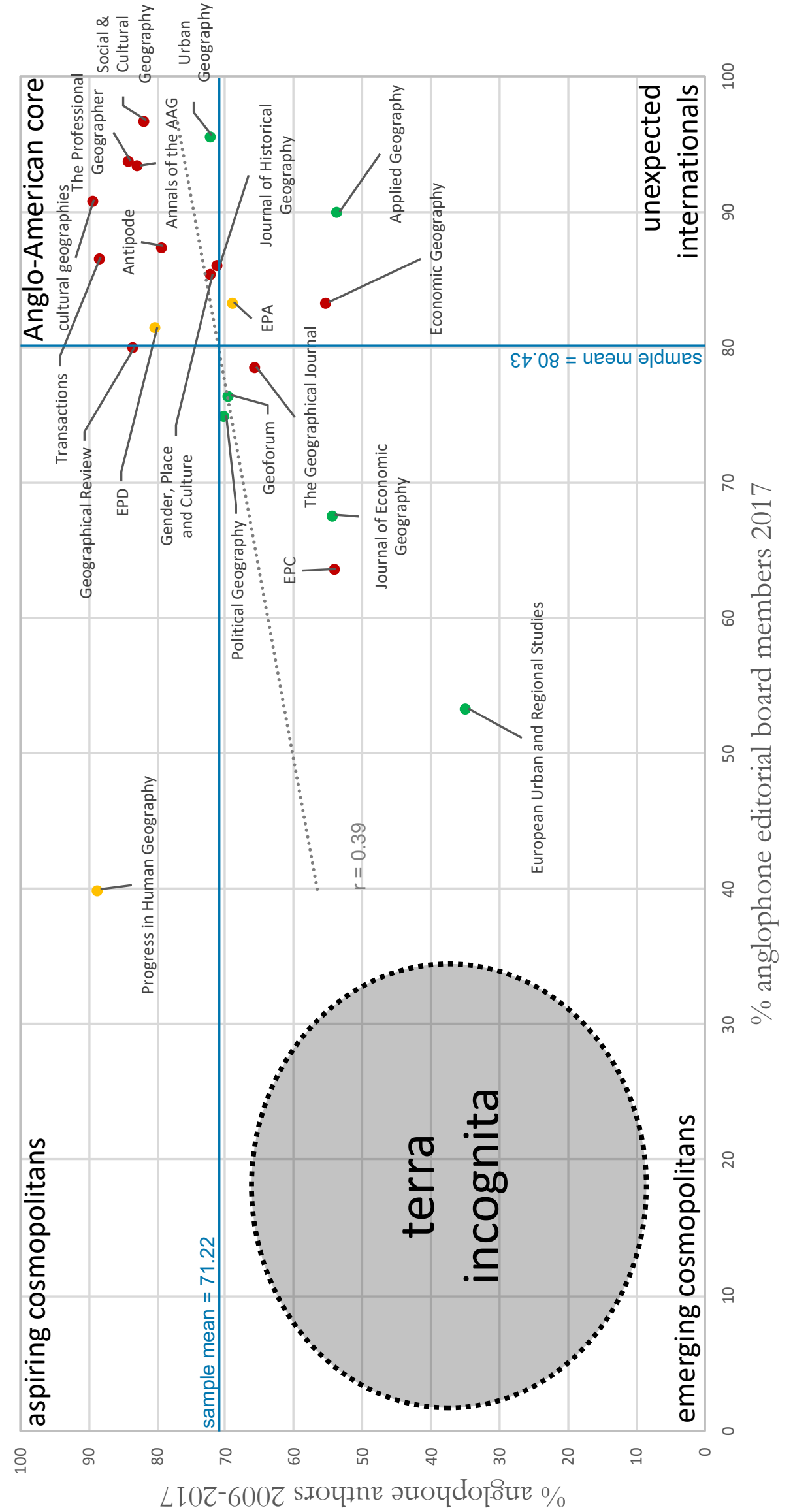

ธ్ర

5. 함

-

过

I 으.ㅁำ

$\vec{v} \bar{y}$

$\exists \stackrel{0}{0}$

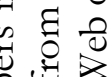

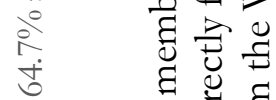

1 चี

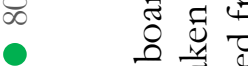

热

零

के

है ह્व

ध ह त्व

굴

营

至.껸

㟧.

ป d

훙

8,4 玒

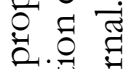

讪. ప

苍究

늉

氙苞芒

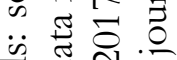

ज

芆司

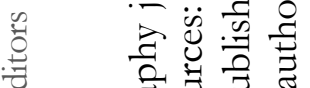

50 o

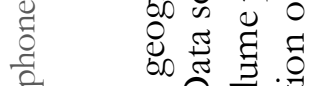

茨用总

离壱焉

एँ

更里

․ㅗㅇ

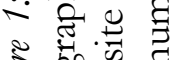

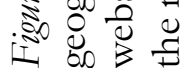


The dotted regression line shows that the share of Anglophone board members is a positive predictor of the share of Anglophone authors. This suggests that putting more non-Anglophone academics in gatekeeping positions could help make authorship more international. Currently, however, only three journals (Progress in Human Geography, Geographical Review, Transactions) have editorial boards that are more international than authors and could lead the way in further internationalization.

Not all places in the world are therefore created equal when it comes to producing what counts as academic knowledge. Our graphic illustrates the existence of a 'geopolitics of knowledge' (Mignolo 2002) in which knowledge created in Anglophone countries is more visible than knowledge produced elsewhere. While journals have become somewhat less Anglophone than they were 20 years ago (Gutiérrez and López-Nieva 2001), they continue to reflect the existence of Anglophone hegemony (Paasi 2005; Ramon, Simonsen, and Vaiou 2006). This is despite a shift in global knowledge production towards the East and South (Gui et al. 2019). It is still a long way for English-language journals to give adequate voice to multiple global knowledges, in the plural; a move of utmost importance in a push to decentre knowledge production (Jazeel 2016; Roy 2009; Trubina et al. 2019).

\section{References}

Gui, Qinchang, Chengliang Liu, Debin Du, and Dezhong Duan. 2019. "The Changing Geography of Global Science." Environment and Planning A: Economy and Space 51 (8): 1615-17. https://doi.org/10.1177/0308518X18816694.

Gutiérrez, Javier, and Pedro López-Nieva. 2001. "Are International Journals of Human Geography Really International?” Progress in Human Geography 25 (1): 53-69. https:// doi.org/10.1191/030913201666823316.

Jazeel, Tariq. 2016. "Between Area and Discipline: Progress, Knowledge Production and the Geographies of Geography." Progress in Human Geography 40 (5): 649-67. https://doi.org/10.1177/0309132515609713.

Mignolo, Walter D. 2002. "The Geopolitics of Knowledge and the Colonial Difference." South Atlantic Quarterly 101 (1): 57-96. https://doi.org/10.1215/00382876-101-1-57.

Paasi, Anssi. 2005. "Globalisation, Academic Capitalism, and the Uneven Geographies of International Journal Publishing Spaces." Environment and Planning A: Economy and Space 37 (5): 769-89. https://doi.org/10.1068/a3769.

Ramon, Maria Dolors Garcia, Kirsten Simonsen, and Dina Vaiou. 2006. "Guest Editorial: Does Anglophone Hegemony Permeate Gender, Place and Culture?” Gender, Place \& Culture 13 (1): 1-5. https://doi.org/10.1080/09663690500530867.

Roy, Ananya. 2009. "The 21st-Century Metropolis: New Geographies of Theory." Regional Studies 43 (6): 819-30. https://doi.org/10.1080/00343400701809665.

Trubina, Elena, David Gogishvili, Nadja Imhof, and Martin Müller. 2019. "A Part of the World or Apart from the World? The Postsocialist Global East in the Geopolitics of Knowledge." Eurasian Geography and Economics forthcoming. 